\title{
7) Tierra de promisión: La Patagonia en los M anuales Estrada durante el primer peronismo
}

\author{
Amelia Beatriz García y Glenda Miralles²
}

\begin{abstract}
Como parte del proyecto de investigación ${ }^{3}$ del que participamos, venimos trabajando sobre las representaciones de la Patagonia en los libros de textos estatales y salesianos anteriores y posteriores al período peronista - fundamentalmente manuales y libros de lecturas. Algunas imágenes que hemos podido identificar en los textos trabajados son las que dan cuenta de: la Patagonia indígena y desierta, la Patagonia petrolífera, la Patagonia como fin de la Patria, a las que se suma la Patagonia turística asi milada a la Suiza Argentina. Estas representaciones fueron producto del análisis de contenidos históricos y geográficos y aquellos referidos a la economía hallados en los textos, plasmadas a través del lenguaje escrito tanto como del lenguaje icónico.

Siguiendo esta línea de trabajo y de un corpus documental de sesenta textos escolares del período peronista, seleccionamos para esta ponencia los M anuales Estrada (M.E.) de dicho período4, teniendo en cuenta que de alguna manera, la práctica política hegemónica del primer peronismo otorgó un carácter incisivo a la introducción de determinados contenidos a través de los textos escolares 5 .
\end{abstract}

1 Docente e Investigadora de la Facul tad de Ciencias de la Educación (UNComhue).

2 Docente e Investigadora de la Facultad de Ciencias de la Educación (UNComhue) - CONICET.

3 Nos referimos al proyecto "Libros de texto. Imágenes y representaciones. la construcción de la Patagonia en el imaginario escolar. Río Negro y Neuquén (1884-1957). Facultad de Ciencias delaEducación (UNComahue), Cipolletti. Directora: Lic. Mirta Teobaldo, Co-Directora: Mg. Amelia Beatriz García.

4 Su tratamiento particular en el cronograma de la investigación obedece fundamental mentea la dificultad que hasta ahora tuvimos de ubicar la documentación pertinente.

5 Si bien no tenemos datos empíricos sobre la implementación en la vida escolar de estas políticas educativas a nivel regional, no dejamos de reconocer que diversas investigaciones han demostrado que existe una distancia entre el currículum prescripto y el currículum vivido. 
Particularmente, y desde una perspectiva cualitativa, haremos hincapié en los contenidos geográficos, históricos y de recursos naturales que permiten ir identificando algunos elementos para definir imágenes de la Patagonia, objetivo central del proyecto de Investigación.

\section{Algunos breves lineamientos del programa peronista}

En principio, si bien, reconocemos la existencia de abundante bibliografía sobre el peronismo y las múltiples líneas de investigación sobre el tema, nuestra intención es concentrarnos sólo sobre algunos aspectos que creemos permiten delinear el contexto socio político del peronismo en el que se inscribe la educación.

Parafraseando a algunos autores que trabajan sobre el período peronista, acordamos que Perón instauró uno de los primeros Estado de Bienestar de América Latina, edificando su hegemonía a partir de la movilización y politización de las clases subalternas, aunque bajo el fortalecimiento del Poder Ejecutivo, de los aparatos del Estado y del Partido. La base de su poder político se constituyó a través de una coalición conformada por los sindicatos, el Ejército y la Iglesia católica, que le permitió durante casi diez años (46-55) acallar a los partidos opositores y reducir su papel en el escenario político.

Durante 1946, el gobierno de Perón publicó su programa económico en la forma de un Plan Q uinquenal de gobierno. El mismo fue un primer esfuerzo tanto de propaganda como de enunciación de una política tendiente a lograr una economía mixta industrial autosuficiente. Otras menciones del Plan se refieren a salud pública, educación, construcción de viviendas y a nuevos beneficios para los trabajadores.

En 1952, se desarrolla una nueva estrategia económica y se publica el Segundo Plan Q uinquenal (Gerchunoff y Llach 2003:201-242). La nueva meta era conseguir el máximo crecimiento de la industria compatible con el equilibrio económico y social. Con respecto a la política nacional para con los territorios, si bien en el Primer Plan Q uinquenal, se plantearon algunos objetivos, recién en 1955 se presenta un proyecto al Congreso que cambia la gradualidad en los procesos de provincialización proponiendo el inmediato cambio de status de Territorio a Provincia de Formosa, Río N egro y N euquén y la creación de dos provincias: la de Chubut, que incluía el eliminado Territorio de Comodoro Rivadavia y la de Santa Cruz que comprendería además de 
aquel territorio a Tierra del Fuego, las Islas del Atlántico Sur y el sector Antártico.

Particularmente en lo educativo, el peronismo planteó las bases que fueron expresadas en el mensaje a la Asamblea Legislativa de 1949 , en la cual se puntualizaba -entre otros- los siguientes principios: Que la conciencia nacional ha de formarse en concordancia con el lenguaje, con la historia, con las tradiciones. Así se afirmaba el concepto de patria y soberanía.

Por su parte el Segundo Plan Quinquenal en materia educativa proponía como "objetivo fundamental: (...) la formación moral intelectual y física del Pueblo sobre la base de los principios fundamentales: la Justicia social, Ia Independencia Económica y la Soberanía Política, armonizando lo valores materiales con los valores espirituales $(. . .)^{\prime \prime}$.

\section{"El Territorio Argentino"”}

Si bien acordamos con Chopin, cuando afirma que el libro escolar, en tanto instrumento del poder, contribuye al nivelamiento cultural y a la propagación de las ideas, particularmente durante el peronismo (Cucuza 2001:210), creemos que el "carácter dominante" que pudiera tener este recurso didáctico estaría matizado por la trama de relaciones y decisiones políticas, administrativas y el accionar cotidiano de maestros y alumnos.

El éxito editorial de los manuales residía en la presencia condensada y sincrética de los conocimientos de numerosos disciplinas, en la funcionalidad pedagógica para la ordenación de la enseñanza y en la mayor economía que representaba para el docente y para los alumnos. En general la presentación de los contenidos se organizaba en "unidades o motivos de trabajo". Uno de ellos es la que figura con el título "El Territorio argentino", que reúne distintos aspectos de la dimensión geográfica, desarrollada a partir del criterio de la división por regiones, descriptas en función del suelo, el clima, la flora y la fauna Esta recurrencia en el tratamiento de la geografía de la nación obedece a un esquema canónico de interpretación del territorio argentino en el sistema escolar: las "regiones geográficas argentinas" (Quinteros

6 Se trata del espiritualismo católico que tiñe el discurso pedagógico de la doctrina peronista. Sobre el tema, ver Puiggrós, 1993.

7 Los subtítul os de este artícul o se corresponden con los utilizados en los Manual es anal izados. 
2002:14-16). Esta división por regiones es una forma de sistematizar las características diferentes dentro de un mismo territorio y de consignar maneras de ver y reseñar esas características.

Específicamente, en los distintos textos trabajados sobre el objeto de investigación que nos preocupa, encontramos una constante en la manera de reseñar las características propias de la región que corresponde a la Meseta Patagónica: "árida, con vientos fríos y secos que desgastan constantemente las rocas (...) que hacen desapacible el ambiente (...) con cañadones que sirven de reparo del hombre y a los ganados y con valles, asiento de prósperas colonias agrícolas (...) los pastos duros como la jarilla el neneo y el calafate son los únicos que viven en las mesetas y alimentan las ovejas una de las mayores riquezas patagónicas" ${ }^{\prime 8}$.

La cuestión agrícola es retomada en otros párrafos en relación al sistema hidrográfico y en ese sentido se menciona el río Negro como un río navegable, origen de un extenso valle, regado por canales y que también constituye uno de los centros de "riqueza de la patagonia por su producción frutal".

La hidrografía de la zona, se presenta bajo el título "Sistema de la Patagonia" estableciendo que su extensión va desde la desembocadura del río Colorado hasta Tierra del Fuego y el Estrecho de M agallanes. El texto invita al lector a observar en el mapa los principales ríos patagónicos, entre ellos los navegables como el "Colorado y el Negro" que cobran importancia para la prosperidad socioeconómica. El perfil que se va delineando en relación a la hidrografía se completa con la descripción de la costa atlántica, que no obstante reconocerse la existencia de pequeñas playas y al gunos refugios para la navegación, se la define "en general inhospitalaria" 9 .

O tro es sin embargo el panorama que se describe sobre la Región andina del Sur, Andes Patagónicos y que completa la representación geográfica de la Patagonia El relato sobre la misma, hace mención a un clima y suelo diferente que permite la formación de bosques y lagos que se ofrecen como preciosos cuadros "dignos de ser observados por los amantes de las bellezas naturales (...) el Nahuel H uapi, Traful, Lacar, Argentino (...)" Es maravilloso el espectáculo de la montañas del sur, cruzadas hoy por buenos caminos que facilitan el turismo

8 Manual Estrada 3er grado 1955:28 y 29; Manual Estrada 4to grado 1951-1959:30 y Manual Estrada 5to grado 1953:19.

9 Manual Estrada 5to grado 1953:34. 
y la actividad comercial"10 (el subrayado nos corresponde). El texto instalaba en la mente del lector una imagen positiva de esta región de la Argentina digna de conocer y apreciar. Asimismo a través de estos contenidos se materializaba la política peronista que impulsaba el turismo social con la finalidad, de "(...) posibilitar el acceso de la población trabajadora a los lugares de turismo", tal como se expresa en el Segundo Plan Q uinquenal ${ }^{11}$.

En el mismo sentido es posible analizar las dos lecturas incluidas en los manuales de 6to grado, del 1952 y del $53^{12}$ referidas al Sur de nuestro país como representación de las bellezas americanas, ubicadas en la unidad "América tierra de promisión", bajo el subtitulo "bellezas naturales". Una de ellas: "los canales fueguinos" de Roberto Payró y otra: "La Suiza Argentina" de Francisco P. Moreno. Ambas reflejan, por medio de una descripción pormenorizada, panoramas de magnífico atractivo. Especialmente significativa resulta la segunda de las mencionadas, pues a través de sus párrafos acercaban al lector a la preocupación del Perito, en el sentido de mostrar y convencer sobre los encantos de la zona contribuyendo también a robustecer dicha imagen positiva sobre la Patagonia andina que "(..) por el magnífico escenario de su naturaleza, en la región de los lagos (...) es la rival de la Suiza europea"13.

En orden a lo geográfico es Ilamativa las diferencias entre la enunciación y el dato cartográfico respecto de la extensión de la Región Patagónica que observamos en Manuales del mismo año de edición. Así en el M.E. 2do. grado (1955:s/fr) se indica la extensión de la región Patagónica en estos términos "Las mesetas del sur del suelo argentino forman la extensa región patagónica que comprende las provincias de Río Negro, Neuquen y Chubut y parte de la de Patagonia"14. Mientras que en el M. E. 3er grado (1955:28) sobre la meseta se dice: "se extiende desde el sur del río Colorado, y desde la Precordillera hasta

10 Manual Estrada 4to grado 1951-1959:25 y Manual Estrada 3er grado 1955:31.

11 2do Plan Qui nquenal 1952, Biblioteca Reservada Peronista del Congreso dela Nación, Bs. As. IX.G.2:153.

12 Manual Estrada 6to grado 1952:22 y Manual Estrada 6togrado 1953:124.

13 Manual Estrada 6to grado 1952:123 y Manual Estrada 6to grado 1953:125.

14 “La extensa provincia de la Patagonia está formada por la extremidad sur del territorio argentino, que comprende la región de Santa Cruz, la parte argentina de la isla Tierra de Fue go, las islas oceánicas y las heladas tierras del Sector Antártico Argentino". Manual Estrada 3er grado 1955:28 (el resal tado es nuestro). 
el océano atlántico, abarcando las provincias de Río N egro, Chubut y Santa Cruz"15. Nótese que en estas referencias no se incluye a Tierra del Fuego; y en la última tampoco se menciona a Neuquén. Sin embargo en el mapa de las regiones geográficas que ilustran la descripción tanto N euquén como la parte argentina de Tierra del Fuego están marcadas conformando la Región Patagónica-fueguina, y ésta última separada de la Región Andina del Sur, Andes Patagónicos.

Igualmente significativa se presenta la relación entre las regiones geográficas y la "vida social y sus costumbres" en su parte 7, en la cual el contenido sobre dicha relación se plantea como "determinante", entre las características geográficas de suelo, el clima y las posibilidades de vida de sus habitantes: "¿Es igual la vida del hombre en cada una de esas regiones? Es evidente que no (...) En la región patagónicofueguina, en cambio, los habitantes recurren a las ropas de abrigo y buscan reparo contra lo fuertes vientos. La actividad preponderante es la ganadería (...) El hombre procura siempre adaptarse al suelo y al ambiente en que habita"16. En este discurso la presencia del determinismo geográfico -propio del pensamiento de la época- buscaba el encadenamiento causal existente entre los fenómenos físicos y los fenómenos humanos. Partiendo de concepciones darwinistas, interrelacionaba el medio natural y los seres vivos y planteaba explicaciones geográficas totalizadoras. En este sentido se pretendía entender la vida humana y la organización del espacio.

Específicamente, para la región en estudio, sobre la "Vida en las Mesetas Patagónicas", los datos son los siguientes: "En la meseta que parece quemada por el viento, no prosperan los cultivos. Los habitantes buscan amparo en los cañadones, (...) Allí se siembra algo de trigo y se cultivan verduras, se logra mantener gran cantidad de ovejas que constituyen la riqueza de la región. La vida del paisano patagónico está ligada a la de sus ovejas o a un jornal (...)". Sin embargo otra es la caracterización de la vida socioeconómica de las mesetas relacionada con la riqueza petrolífera de Comodoro Rivadavia y la vida socioeconómica de sus residentes. Se define a la ciudad como "progresista" identificándola como un centro importante de explotación de petróleo, donde sus habitantes, "habituados a los fuertes vientos, viven con

15 Lo relevante a destacar es que se trata de dos ediciones de 1955, en los que se menciona Santa Cruz o Patagonia indistintamente sin tener en cuenta el decreto de 1954 que creó, si bien por un breve lapso la Provincia de la Patagonia.

16 Manual Estrada 3er grado 1955:205. 
comodidades parecidas a las que pueden brindarles las grandes ciudades de las zonas fértiles". Esta situación de bonanza da pie a la afirmación del texto que queremos destacar: "Podemos decir que la zona patagónica ya no es un desierto como lo era hace unos veinte años".

Creemos que esta última afirmación usada para presentar los contenidos traduce el pensamiento de Perón respecto de la Patagonia tal como está expresado en el Segundo Plan Quinquenal en una nota a pie de página: "como lo ha dicho tantas veces el general Perón la Patagonia es la Tierra de promisión de los argentinos. El siglo venidero le dará la razón en ese sentido".

El mosaico de regiones geográficas se transformó en la imagen más fuerte que la geografía escolar proponía para interpretar el territorio; en función de describir la hidrografía, el suelo, la flora y la fauna, como así también las características de las ciudades, la vida y las costumbres y las actividades económicas. En este sentido, bajo el ideario peronista, se consolida - lo que Quinteros denomina- "una versión esencialista de la regionalidad (...) [en la cual] la representación del territorio como un rompecabezas estático de formaciones naturales y humanas, provoca una ilusión de inferencia inductiva cuyo resultado pretende ser la unidad nacional argentina".

Esta idea de unidad nacional a partir de la geografía se refuerza con la construcción discursiva observada en el M. E. para 4to grado de 1951, bajo el título "La Patria y el lugar nativo". Es una introducción al tratamiento de las regiones en la cual se plantea la vinculación entre la realidad geográfica de la nación con la idea de Patria. A nuestro criterio, la importancia de este vínculo, amerita la extensión de la cita: "Los extensos territorios de nuestro país que hemos examinado en los mapas forman la unidad geográfica nacional (con cursiva). Son nuestro patrimonio, es decir la base material de la Patria. Pero forman parte también de ella las riquezas naturales, las ciudades, los pueblos, los campos sembrados, los valles poblados de ganado. Y constituyen sus fundamentos las tradiciones históricas (...) La patria es todo eso: el suelo, y su riqueza, nuestros conciudadanos, nuestros hogares y nuestras tradiciones. La Argentina constituye una nación rica y poderosa, cuyo suelo se extiende desde las cálidas regiones del norte hasta las heladas e inhospitalarias tierras e islas australes. Por la unidad de ese territorio los argentinos estaremos siempre dispuestos a dar nuestra vida si fuera necesario. Dentro de la patria hay muchas regiones y lugares distintos. Conocemos bien el lugar que ha nacido, (...) Es el 
lugar nativo. No olvidemos sin embargo que el lugar nativo es una pequeña parte de la patria y que tan argentinos son nuestros vecinos como los habitantes de las apartadas regiones del país. Nacidos en las Malvinas, todos somos argentinos y por sobre el cariño al lugar nativo ponemos el amor a la Patria que nos une a todos bajo una sola bandera"17.

Si bien este párrafo fundamenta la importancia de las regiones geográficas aludiendo a la idea de Patria, ésta no se reduce a elementos materiales-geográficos sino que se plantea para su definición una suerte de tensión entre lo tradicional y lo modernizante. Con relación a esta tensión, por un lado adherimos a los comentarios de Silvina Q uinteros sobre el sentido de la literatura regional, en la que lo tradicional y lo nativo se romantizan "frente a la anterior idealización de la inmigración europea" (Quinteros 2002: 26). Por otro, la Patria también aparece vinculada con la idea de progreso material.

Los aspectos geográficos que hasta aquí hemos detallados, especialmente las descripciones del suelo, la flora y la fauna, ido el paisaje están acompañados por un lenguaje icónico que de algún modo refuerza lo expresado por el lenguaje escrito. Se trata de dibujos bien definidos de líneas simples, con marcado sentido didáctico que en pequeños recuadros muestran algún ejemplar de la flora, la fauna o una vista de la meseta Patagonica ${ }^{18}$; en otros casos el texto está ilustrado con fotos también en blanco y negro, sobre los canales fueguinos, o algún panorama de la región de los lagos cordilleranos. La fotografía recurrente es una imagen del Lago $\mathrm{N}$ ahuel Huapi ${ }^{19}$.

Del mismo modo que los aspectos geográficos analizados conducen a construir una representación de la Patagonia, a nuestro criterio, también los datos sobre la división política cobran importancia pues permiten ir delineando una imagen sobre la región estudiada. Al respecto el mapa de la República Argentina que contiene el Manual de 5to grado de 1953 muestra las modificaciones geo-políticas. Por un lado aquellas referidas a los cambios en las denominaciones de la Provincias del Chaco y La Pampa por Presidente Perón, y Eva Perón respectivamente. Por otro los cambios en la cartografía de la parte

17 Manual Estrada 4to grado 1951-1959:10.

18 Por ejemplo en el Manual Estrada de 3er. grado 1955:28 y 29 la página que describe la meseta Patagónica está diagramada con tres dibujos que se intercalan con el texto correspondiente: a un al erce, a la mara o liebre patagónica y un dibujo de la meseta patagónica.

19 Manual Estrada 5to grado 1953:18 y 31. 
Sur del país, fijando entre Chubut y Santa Cruz la Zona Militar de C. Rivadavia.

Igualmente, en esta línea de anál isis es importante tener en cuenta que durante el gobierno de Perón por un decreto en 1954, desaparece Santa Cruz y se crea la provincia de la Patagonia, esta creación estuvo vigente hasta 1956. En relación con esa modificación en el mapa del territorio nos encontramos con dos ediciones de M. E. de 1955 para 3er grado con datos diferentes: una menciona Patagonia y en otra Santa $\mathrm{Cruz}^{20}$ como jurisdicciones provinciales. Al respecto podríamos conjeturar que tal discrepancia podría estar dada por el término de la impresión de uno de los textos: marzo de 1956, pues en ambos la autorización de M inisterio corresponde a un expediente de 1955.

\section{"N uestro panorama económico"}

En relación a la Patagonia, en los Manuales Escolares, tanto el ganado ovino, como las riquezas naturales de la tierra (el petróleo, los minerales (carbón, hierro, hulla) y el acero), funcionaron como soporte para la construcción de una representación de esta región. En los textos trabajados, se hace referencia a los lugares de la Patagonia que cuentan con riqueza minera: "El petróleo ocupa hoy el primer lugar entre los combustibles nacionales. Los yacimientos más importantes se hallan junto al Golfo de San Jorge distribuidos en varias zonas: C. Rivadavia, Colonia Escalante, Colonia Sarmiento y Caleta O livia (...) le siguen en orden entre otras los de Plaza Huincul (Neuquen)"; Con respecto a la hulla, lignito y carbón hoy se extraen en la región del río Turbio al sudoeste de Santa Cruz (...) otras explotaciones de lignito son los yacimientos de Río N egro y Neuquen (...); hay yacimientos de turba en distintas regiones de nuestro país (...) [entre otras] Chubut y Tierra del Fuego"21.

Creemos que el discurso escolar que encierran los $M$ anuales se hace eco de la política económica del período peronista. Ejemplo de ello es la información que se brinda al alumno respecto de la "Política Minera de la Nueva Argentina": "Hasta hace pocos años, (...) la minería y la industria no tenían importancia para la economía (...)

20 El decreto ley N 21.178/ 56, disponela constitución dela Provincia deSanta Cruz, -capital Río Gallegos- desapareciendo en consecuencia la Patagonia como jurisdicción provincial.

21 Manual Estrada 5to grado 1953:291-297 y Manual Estrada 6to grado 1952:264-267. 
El cambio no es obra de la casualidad, ni de la simple evolución natural: es consecuencia del nuevo ritmo impuesto a la República por el gobierno justicialista del General Perón"22. Las ediciones 1952 y 1953 contienen un pormenorizado tratamiento de los temas referidos a la extracción de las riquezas naturales en concordancia con lo delineado en el Segundo Plan Quinquenal, bajo el titulo: “Exploración y Explotación Minera"23. Las palabras de Perón son claras señalando la intención del gobierno en dicho tema: "Hemos venido preparando en los años pasados todos los mecanismos necesarios para que el $2 \mathrm{do}$ Plan Q uinquenal se caracterice como el Plan de la minería"24. Este accionar previo al cual hace referencia Perón, aparece plasmado como contenido en los Manuales de 1951. La transposición didáctica debía orientarse a la "formación de la conciencia minera nacional"25. En estos términos se expresa en el Segundo Plan Quinquenal el objetivo a lograr con la transmisión de contenidos sobre dicho tema en el ámbito de la escuela.

En consecuencia el M. E. para 5o grado de 1953, dedica dos páginas a la información referida a la extracción y destilación del petróleo ${ }^{26}$, del mismo modo que presenta un detallado relato sobre el proceso de extracción de minerales como el carbón, manganeso, azufre, hulla, etc. ${ }^{27}$ Entre la información específica sobre el tema destacamos estos datos: "en los últimos años se ha construido el gasoducto Presidente Perón que lleva directamente el gas de los pozos de Comodoro Rivadavia hasta la Capital Federal, para facilitar su aprovechamiento (...) en nuestro país se han instalado grandes plantas de destilación y refinado. Las principales corresponde a YPF (...)" ${ }^{28}$. LoS mismos reflejan el uso de los Manuales Escolares como instrumentos de conocimiento de las obras realizadas por el gobierno de turno, con

\footnotetext{
22 Ibidem: 308.

232 do Plan Quinquenal, op. cit:212.

24 2do Plan Quinquenal: 214-215.

25 Ibidem, XII - G - 20- pág. 219.

26 En el Manual se hace referencia a la importación de petróleo, necesario para el desarrollo industrial y a consecuencia de la falta de maquinaria apropiada (Manual Estrada 6to grado 1952:267.

27 El tema esta detalladamente ilustrado con esquemas explicativos sobre la extracción de minerales, el procedimiento de destilación en el caso del petróleo, esquemas sobre horno de acero.

28 Manual Estrada 5to grado 1953:291.
} 
el convencimiento que la "función social de los combustibles" debía responder al principio peronista: "primero la felicidad del Pueblo y luego concurrentemente la grandeza de la Nación, toda vez que no se puede hacer la grandeza de la Nación sin la felicidad del Pueblo"29.

Asimismo los contenidos que observamos en el M.E. de 1953 respecto del "Régimen de explotación", "Intervención del Estado", ponen sobre el tapete el accionar intervensionista de la política peronista en la dirección y regulación de la economía. Al respecto en uno de los textos analizado se expresa: "¿por qué es necesario solicitar permisos especiales para la explotación de las minas? La explicación esta en los términos del art. 40 de la Constitución $\mathrm{N}$ acional. De acuerdo con esta disposición las minas no pueden ser de propiedad privada: son del Estado, es decir deben explotarse para beneficio del pueblo o la seguridad de la Nación (...) el Estado propietario de las minas puede reservarse en sus zonas los espacios que crea convenientes para explotación directa. En estas reservas fiscales no se conceden cateos ni pertenencias privadas." ${ }^{30}$. También, los manuales dan cuenta de los lineamientos de esta política denominando minerales críticos (petróleo, hulla, hierro y manganeso) a aquellos que son indispensables para la defensa nacional o la seguridad del Estado y que se vinculan con la industria metalúrgica del acero ${ }^{31}$.

En intima relación con esta temática, se ofrece al lector detalles sobre las condiciones para el éxito de la industria minera como las vías de comunicación y los medios de transporte, haciendo referencia, entre otras, al progreso material de algunas zonas de la región Patagónica: "Es el problema que ha tenido durante mucho años de explotación en nuestra zona cordillerana alejada de los grandes centros poblados (...) en los último años la construcción de algunas líneas férreas y buenos caminos han permitido la explotación activa en estos lugares (...) Las minas de Río Turbio, en Santa Cruz se hallan unidas por un camino afirmado y por la línea férrea Eva Perón que une Río Turbio con Río Gallego con fácil salida al mar" ${ }^{32}$.

Todo el discurso informativo sobre el progreso de esta región, presenta una constante en los textos del período que hemos tenido

29 2do. Plan Quinquenal op.cit. Nota de pie de página № 194:233.

30 2do Plan Quinquenal: 299.

31 Manual Estrada 5to grado 1953:294 y 295.

32 Manual Estrada 5to grado 1953:297 y 308. 
oportunidad de examinar. Se trata de una enunciación en la cual el peronismo representa el cambio, proponiendo acciones superadoras que emergen después de un "un estado de crisis" y "de una nación detenida": Es maravilloso el espectáculo de las montañas del sur, cruzadas hoy por buenos caminos que facilitan el turismo y la actividad comercial" 33 ; "H oy los yacimientos de Comodoro Rivadavia constituyen una importante riqueza nacional" 34 ; Actualmente las condiciones de labor del minero son mejores" 35 .

Las expresiones resaltadas ilustran nuestro comentario sobre la estrategia discursiva, en la cual los adverbios "hoy" y "actualmente" remiten a un opuesto: el Ayer que implícitamente queda descalificado. Sin embargo, hallamos que esta descalificación sobre el pasado de la Patagonia se hace explícita en el M.E. de 5to grado de 1953: "El carbón de piedra de la Patagonia se conocía antes de 1946, pero la explotación era casi nula; el gobierno de la Nueva Argentina ha iniciado la explotación en gran escala..." ${ }^{\prime 36}$; y en el Segundo Plan Q uinquenal: "Desde fines del siglo pasado los argentinos sabíamos que el carbón de Río Turbio era tan bueno como ningún otro, pero tuvo que venir Perón para que el carbón de Río Turbio fuera utilizado"37.

Además de la independencia económica otras de las claves de la política peronista tuvo que ver con los trabajadores, con el mantenimiento del empleo y la elevación de su nivel de vida (Romero 1994:129-177). Bajo el título "El Minero", en el Manual de 5to grado del 53, apelando nuevamente a la crítica de sus antecesores, se traza una "semblanza de una vida de penurias", para terminar enumerando las mejores condiciones del trabajador de las minas, concretadas en las leyes que lo protegían y explicitando además, el reconocimiento de todo el pueblo por la labor realizada; temas también presentes como contenido escolar. Igualmente queremos destacar de los M anuales de

33 Manual Estrada 4to grado 1951-1959:24.

34 Manual Estrada 5to grado 1953:267.

35 Manual Estrada 5to grado 1953:296.

36 Manual Estrada 5to grado 1953:308.

37 Las características que adquiere la presentación de estos contenidos en los textos escolares, responden a la particularidad de la segunda etapa del discurso peronista, de acuerdo a la periodización real izada por Emilio De I pola. Puntual mente la acentuación del antagonismo corresponde al período que se extiende desde fines de 1945 hasta 1951, fines de la segunda presidencia (De I pola 1983:143). No obstante, la presentación de otros conteni dos mostrados en párrafos anteriores, corresponderían más a la tercera etapa del discurso, en el cual va desapareciendo dicho antagonismo. 
este período ${ }^{38}$, la vinculación de la religión con el tema: "Riqueza Minera", respondiendo a la Correlación informativa entre las distintas asignaturas con la Moral y la Religión establecida desde la política educativa peronista (Teobaldo y García 2007:15-17).

En este sentido la referencia al culto a "Santa Bárbara" como la "Santa Patrona de los Mineros" está presentada de este modo: "Desde hace muchos siglos los hombres que ejercen un mismo oficio o profesión ponen sus actividades bajo el patrocinio de un santo. (....) Dentro del mundo cristiano Sta. Bárbara es la patrona de los mineros. Los oscuros y humildes trabajadores de las subterráneas galerías se encomiendan a ella antes de comenzar su diaria faena, tan llena de peligros"39.

Finalmente, en materia de lenguaje icónico, como lo expresamos en párrafos anteriores, creemos que las ilustraciones en líneas generales acompañan y reafirman el mensaje lingüístico del texto, ya se trate de esquemas en el caso del tema del petróleo ${ }^{40}$ y otros minerales; de mapas con la ubicación de los distintos yacimientos ${ }^{41}$; 0 de fotos en blanco y negro como la vista de Comodoro Rivadavia acompañada de una epígrafe explicativo que refuerza la imagen tomada, y que dice: “C. Rivadavia es la población más importante de la costa patagónica. Es el centro principal de nuestra industria petrolera" 42. En el primer plano de la foto, una fila de autos de la época, connota la imagen y nos parece significativo como testimonio de la riqueza y el progreso de la zona. O tra foto, en el mismo Manual, muestra dos mineros en el interior de una galería de carbón de Río Turbio, junto a la vagoneta transportadora del mineral ${ }^{43}$.

\section{"Hacia los grandes destinos"}

Desde otra perspectiva, se refuerza la representación sobre la Patagonia registrada a través de los contenidos que desarrollan la di-

38 Algunos Manuales incluyen un Suplemento con el desarrollo de los programas de religión católica.

39 Manual Estrada 5to grado 1953:296 y 297.

40 Manual Estrada 6to grado 1953:268 y 269, Manual Estrada 5to grado 1953:290, 291, 294.

41 Manual Estrada 6to grado 1952:265.

42 Manual Estrada 5to grado 1953:296.

43 Manual Estrada 5to grado 1953:282. 
mensión histórica. Al respecto se plantea cierta correspondencia entre espacio y habitante, mostrando la distribución geográfica y caracterización de los "indígenas" 44 .

En el caso específico que nos ocupa, se hace mención a los indios araucanos - de M endoza y Neuquen- patagones - de Río N egro, Chubut y Santa Cruz- y onas de Tierra del Fuego. En relación a cada una de las tribus, se puntualizan distintos aspectos referidos a la alimentación, la vestimenta, la construcción de sus viviendas, las actividades y sobre algunas costumbres. Tanto en el M. E. para 3er grado de 1951 como para el de 1955, los patagones se presentan en estos términos: "Se llamaba así a los habitantes de Río Negro, Chubut y Santa Cruz (Patagonia) verdaderos gigantes comparados con los otros indígenas (...) Sus tiendas estaban hechas con palos y cueros... vivían del producto de la caza. Aguerridos, bien armados, con arcos y flechas constituyeron también un serio obstáculo para la conquista: los españoles no lograron establecerse en la Patagonia"45. Mientras que en el M. E. de 4to grado de 1951, el tratamiento de este tema se refiere al "grado de cultura de los aborígenes" caracterizándolos de acuerdo a su mayor grado de "civilización o salvajismo". En el caso de las tribus que habitaban la Patagonia, los araucanos son calificados como "más civilizados que los puelches" y los patagones como "de costumbres salvajes".

En los textos se mantiene el esquema de presentar a los "aborígenes" de la Argentina agrupados según regiones geográficas, como parte del ámbito natural. Pareciera ser que se vincula la naturaleza con el hombre integrado a ella. "El suelo modela al habitante del nuevo mundo, lo "naturaliza" (...) por ello la misma tierra otorga singularidad a la población que la ocupa, afirmación que se remonta al determinismo geográfico de la época" (Q uijada 2000:186).

Asimismo, esta temática sobre el "indígena", vuelve a estar presente en las unidades tituladas "Organización Nacional" y "Hacia los grandes destinos" haciendo mención a la constitución de la población argentina y a las acciones desarrolladas por los distintos presidentes. Con respecto a la población de la región media del país (Bs. As, Córdoba y Mendoza) se la presenta integrada "netamente por el elemento

\footnotetext{
44 Utilizamos las denominaciones "indígena/s", "indio", "puebl os indígenas" o "aborigen" en función de la terminol ogía que encontramos en los Manuales Escolares, aunque advertimos queel concepto "indio" es un concepto acuñado desde la cultura dominante.

45 Manual Estrada 3er grado 1955:74.
} 
blanco", fruto de la inmigración europea, sin mezcla alguna con el "indígena" el cual, a consecuencia del desalojo de fines de siglo XIX, ocupaba la Patagonia. En este sentido los M anuales expresan: "Ia Patagonia era totalmente tierra de indios" ${ }^{46}$; "el indígena (...) desapareció poco a poco de las mesetas y valles de los ríos, se concentró en la cordillera donde aún hay algunos grupos que no se adaptan a nuestra civilización" ${ }^{47}$. Esta explicación estaría dando cuenta de un discurso opuesto respecto del lugar en el que se lo ubica al "indígena"; o bien, formando parte del pasado histórico: los habitantes de la Patagonia aparecen arqueologizados (Q uijada 1996:243-269, 1998:20-46), y se produce la paleontologización del otro (Andermann 2000:124-125). 0 como habitantes del presente, pero marginados (el subrayado es nuestro).

O tra información recogida de los textos analizados, está referida a relatar la lucha contra los "indígenas" en las campañas del desierto. Creemos que un dato a destacar son los términos con los cuales es descripta la primera de las campañas, durante el gobierno de Rosas, que difieren según los años de edición de los Manuales. Mientras que en 1953 se habla de "la Dictadura de Rosas", en ediciones de 1952 y 1955 se refiere a "La época de Rosas". Sin embargo en cuanto a los términos que utilizan para describir la acción contra los "indios" son similares: "Rosas (...) preparó y realizó con todo éxito una expedición contra los salvajes, Ilegando hasta el territorio de Neuquén. (...) había rechazado a los indios hacia la Patagonia, estableciendo los primeros fortines; (...) expuestos a los malones que sembraban el terror entre los pobladores" 48. "actuó con gran energía, batió a los indígenas en muchos encuentros y los persiguió hasta la Patagonia, después estableció fortines (...) Por esta gesta se le dio el título de "héroe del desierto"49.

Haciendo una digresión y considerando los datos recogidos en los Manuales Estradas del período peronista, creemos que el tratamiento de la figura de Rosas se presenta como contradictoria si tenemos en cuenta estos subtítulos: "Dictadura de Rosas" y "La época de Rosas". En este sentido, si bien parece existir una revisión sobre su imagen, sigue estando presente la visión más tradicional. La acción "civilizado-

46 Manual Estrada 4to grado 1953:314.

47 Manual Estrada 5to grado 1953:357.

48 Manual Estrada 4to grado 1953:266.

49 Manual Estrada 3er grado 1955:72 y 74.

- Instituto de Estudios Socio-Históricos - Facul tad de Ciencias Humanas - Universidad de La Pampa- 
$\mathrm{ra}^{\prime \prime}$ de Rosas alude a la permanencia de una tendencia de incorporarlo "en la historia aceptada como legítima, más que un intento de reemplazar una historia oficial por otra, como intentaban los revisionistas" (Plotkin 1994:197).

Igualmente los manuales del período peronista presentan la "Conquista del Desierto" bajo la dirección de J.A. Roca durante la presidencia de Avellaneda, con el objetivo de "incorporar la Patagonia a la civilización"50; o la mencionan como continuación de las acciones iniciadas por Alsina para "pacificar las tribus patagónicas" 51 . Se rescata la figura de Roca en la lucha contra el "indígena", batiendo a los salvajes y arrasando sus tolderías. El resultado de esta acción militar, fue que "en 1879, la bandera flameara a orillas del Lago Nahuel Huapí. Los indios huían hacia el sur de la Patagonia, o se sometían al gobierno nacional" 52 . El binomio civilización/ barbarie, propio del período de construcción del Estado nacional, de alguna manera sigue estando presente en los textos peronistas. El indio, el desierto, la Conquista se constituyen en una cadena de significados que adquiere sentido, en "la conquista de la Patagonia, ocupada hasta entonces por indios salvajes" 53 .

La Conquista, a excepción del resto de los Manuales, en el de 4to grado 1953, se desarrolla bajo el título "Evolución de la sociedad argentina después de 1853 "para todos lo hombres del mundo". En el marco de esta noción y pensada desde una perspectiva positivista, se la presenta como un antecedente de la inmigración europea: "La campaña del general Roca, dio a la civilización muchos kilómetros de campo, hacia los cuales empezó a dirigirse el torrente inmigratorio. Iba a comenzar la época en que la agricultura y la ganadería constituirían la gran riqueza nacional ${ }^{54}$. Aquí el sentido de la recuperación de las tierras se inscribe dentro del esquema del nacionalismo peronista en el cual la Justicia social, la soberanía política, el bienestar, la independencia económica y el progreso fueron las claves de su discurso

\footnotetext{
50 Manual Estrada 5to grado 1953:357.

51 Manual Estrada 6to grado 1953:351.

52 Manual Estrada 4to grado 1953:314 y 315.

53 Manual Estrada 6to grado 1953:236.

54 Manual Estrada 4to grado 1953:315 y Manual Estrada 6to grado 1952:234.
} 
sobre el cual se basaba el perfil nacionalista y popular de la "Nueva Argentina" 55 .

En referencia a las ilustraciones, son escasas con respecto al tratamiento del tema del "indígena" y a la conquista del desierto. En el corpus documental trabajado, sólo hallamos dibujos en blanco y negro; uno representando el fortín, otro las tolderías de los "indígenas" y finalmente algunos textos incluyen retratos de las figuras destacas en las acciones militares, tales como: Rosas y Roca. Destacamos la leyenda que acompaña el dibujo del fortín: "allí vivían en precarias condiciones los soldados que luchaban contra los salvajes, cuyos ataques eran a veces incontenibles"56.

En el caso de los dibujos, la característica del mensaje, a diferencia de la fotografía, radica en la presencia, casi absoluta de la connotación. El dibujo, aunque denotado es un mensaje icónico codificado. La denotación es menos pura que en la fotografía, pues el estilo del autor carga de significados el objeto elegido para su representación (Barthes 1970:115-140). En cambio el mapa de referencia observado en el M anual de $V$ grado de 1953 indica el itinerario de la expedición al desierto de Rosas, Alsina y Roca y de los territorios conquistados. Esta imagen es una pista para entender los detalles, y cumple una función informativa y explicativa.

\section{Algunas anotaciones finales}

El recorrido por los Manuales escolares nos permite esbozar algunas reflexiones teniendo en cuenta los aspectos que fundamentalmente trabajamos en el cuerpo del artículo: el geográfico, el referido a las riquezas de la región y el histórico. No obstante consideramos que no se reducen a estos contenidos la información hallada en los Manuales, que posibilitan la construcción de representaciones sobre la Patagonia ${ }^{57}$.

Con respecto a la información geográfica la imagen más claramente delineada de la región en estudio es dual, en tanto La Patagonia se presenta como un espacio árido e inhospitalario, y a su vez como

55 Cfr. Girbal-Blacha 1997 y Rock 1991.

56 Manual Estrada 4to grado 1953:311.

57 Nos referimos específicamente a aquellos contenidos que dan cuenta de las cuestiones de soberanía sobre laA ntártida e Islas Malvinas, trabajadas en otra publicación. 
una zona de bellezas naturales que posibilitan el turismo y la actividad económica. El "turismo" fue un aspecto que se vio favorecido por ciertas acciones del Estado central hacia estas regiones del Sur Argentino. No permaneció al margen de los cambios que se producían en las políticas sociales durante la Presidencia de Perón. A partir de 1946, la política se orientó a la reasignación de recursos para la producción y al desarrollo de una estrategia de distribución del ingreso, esto significó la promoción del turismo social posibilitando el acceso masivo a esta región.

El discurso escolar sobre las "regiones geográficas", se vio reforzado por el acento regionalista del Segundo Plan Q uinquenal, que intentaba superar las diferencias entre las distintas zonas del país. En ese sentido una expresión identificada en uno de los manuales traduce el pensamiento de Perón respecto de la Patagonia: "Ia zona patagónica ya no es un desierto como lo era hace unos veinte años".

Del mismo modo, creemos que el discurso escolar que encierran los Manuales se hace eco de la política económica del período peronista que a partir de 1952 impulsa acciones de aliento al sector primario. En concordancia con esto, la descripción geográfica, menciona tanto la cría de ovejas, como el desarrollo de la fruticultura en el Alto Valle.

Por su parte en relación a la riqueza del suelo, el núcleo de la representación de la Patagonia giraba en torno a ser un espacio de concreción de la Política Minera para la Nueva Argentina. En este sentido la transposición didáctica debía orientarse a la "formación de la conciencia minera nacional" que implicaba la lucha por la soberanía y la independencia económica. Es así como los Manuales se constituyeron en instrumentos de propaganda política, desplegando detalladamente contenidos acerca de la ubicación de los yacimientos de petróleo y otros minerales en toda la extensión de Argentina y su consecuente proceso de extracción. En particular sobre el Sur de país, el dato a destacar es el que daba cuenta de "el gasoducto Presidente Perón", la vía férrea Eva Perón y lo que estas obras representaban para el progreso de la Nación. De este modo la prédica escolar, referida a la construcción de la imagen de la Patagonia como emblema del progreso, estuvo atravesada por la "peronización" de los contenidos.

En esta dirección otro aspecto a considerar es la introducción que, partiendo desde lo regional, construye la idea de "unidad geográfica nacional", plasmada en la noción de Patria. La Patagonia frecuente- 
mente asociada a "lugar apartado del país", desde el discurso escolar aparece revalorizada, como así también sus habitantes, bajo el lema "todos somos argentinos". En el accionar ideológico de la escuela, el alumno fue uno de los protagonistas de este mensaje elegido por el oficialismo, con la intención de generar en ellos "el amor a la Patria, que une a todos bajo una sola bandera".

Por su parte de la dimensión histórica, queremos resaltar lo que a nuestro entender constituye una "dualidad" discursiva presente en el corpus documental analizado respecto del tratamiento de la figura del "indio". En alguno de los manuales analizados, el "indio" es considerado como parte del pasado, y en ese sentido, los habitantes de la Patagonia aparecen arqueologizados. En esta línea de análisis, estos textos peronistas, mantienen la oposición civilización / barbarie heredada de períodos anteriores. Mientras que en otros Manuales Estrada del mismo período observamos que el "indio" es reconocido como habitante de la patagonia, en el presente, pero a la vez marginado.

Advertimos que la política indigenista del período peronista, se plasma no sólo en el capítulo I "Organización del pueblo. Población" del Segundo Plan Q uinquenal ${ }^{58}$, sino también se hace efectiva con la creación de la Dirección de Protección al Aborigen (1946), las reformas de la Constitución de 1949 y con la conformación de la Comisión de rehabilitación para la explotación de tierras (1953) (Lenton 1998 y Argeri 2004:72-78). Sin embargo, este sesgo reivindicativo no está considerado en los contenidos de los Manuales.

La preocupación del gobierno de Perón, en referencia a la cuestión "aborigen" se vincula con la necesidad de incorporarlos a la vida activa nacional, tanto respecto de lo económico (proletario), como en el ámbito político (ciudadano). Sin embargo nos parece oportuno detenernos en algunas expresiones del discurso escolar que encierran los textos investigados. Del indígena, habitante de la Patagonia se dice: "aún hay algunos grupos que no se adaptan a nuestra civilización". El enunciado es lo suficientemente significativo para permitirnos inferir que, con la propuesta de adaptación se encubren, en el proceso de

58 El esquema de la pag. 43, los incluye bajo el título "protección del aborigen" como parte del "Capital Humano". En el subtítulo "Protección del aborigen", se lee: "La población indígena será protegida por la acción directa del Estado mediante la incorporación progresiva de la misma al ritmo y nivel de vida general de la Nación". Y la nota al pie aclara: “A pesar de que en nuestro país el aborigen representa un núcleo muy reducido de la población, el zo Plan Quinquenal le dedica este objetivo general porqueel poblador autóctono ha merecido siempre la afectuosa preocupación de nuestro Presidente" (1952:13-14). 
Amelia Beatriz García y Glenda Miralles

incorporación, relaciones de desigualdad y no-reconocimiento de particularidades que hacen a una heterogeneidad cultural.

\section{Corpus Documental}

M anual Estrada 2do grado (1955), Buenos Aires.

M anual Estrada 3er grado (1951), Buenos Aires.

M anual Estrada 3er grado (1955), Buenos Aires.

M anual Estrada 4to grado (1951-1959), Buenos Aires.

M anual Estrada 4to grado (1953), Buenos Aires.

M anual Estrada 5to grado (1953), Buenos Aires.

M anual Estrada 6to grado (1952), Buenos Aires

M anual Estrada 6to grado (1953), Buenos Aires.

Primer Plan Q uinquenal (1947), Buenos Aires.

Segundo Plan Quinquenal (1952) Biblioteca Reservada Peronista, Congreso de la Nación, Buenos Aires.

\section{Referencias bibliográficas}

AD ERM AN N, Jens (2000) M apas de poder. U na arqueología literaria del espacio argentino, Buenos Aires, Vierbo.

ARGERI, María Elba (2004) "Los indígenas de Río Negro en el estado peronista", en: Todo es H istoria no 449, Buenos Aires, pp.72-78.

BARTHES, Roland (1970) "El mensaje fotográfico" en R. BARTHES y otros La Semiología, Buenos Aires, Tiempo Contemporáneo, pp. 115-140.

CUCUZZA Héctor y SOMOZA Miguel (2001) "Representaciones sociales en los libros escolares peronistas. Una pedagogía para una nueva hegemonía", en: G. OSSENBACH y M. SOMOZA RO D RIGU EZ Los manuales escolares como fuentes para la Historia de la Educación en América Latina, M adrid, U NED, pp. 209-244.

DE IPO LA, Emilio (1983) Ideología y discurso populista, Buenos Aires, Folio Ediciones. 
GARCÍA, Amelia Beatriz y MIRALLES, Glenda (2007) “Entre el ocaso del Territorio y el futuro de la Provincia: La Patagonia en los M anuales Escolares en uso en escuelas rionegrinas (1955-1959)", en: Actas Pedagógicas, año 5,no 3, diciembre, Cipolletti, pp. 79-90.

GERCHUNOFF, Pablo y LLACH, Lucas (2003) "Del paraíso peronista a la crisis del desarrollo (1949-1958) en El ciclo de la ilusión y el desencanto, Buenos Aires, Ariel, pp. 201-242

GIRBAL-BLACHA, N oemí (1997) Historia y cultura en la construcción del discurso político peronista (1946-1955), CONICET/ UNLP / UNQ , Argentina, (mimeo).

LENTON, Diana (1998) "Los indígena y el Congreso de la Nación Argentina: 1880-1976" [en línea] www.naya.org.ar.

PLOTKIN, Mariano (1994) “La politización de la educación: los libros de texto "peronistas" para escuelas primarias en Mañana es San Perón, Buenos Aires, Riel, pp. 171-208.

PUIGGRÓS, Adriana, dir (1993) Peronismo. Cultura política y educación, Buenos Aires, Galerna.

QUIJADA, Mónica (2000) “Imaginando la homogeneidad: la alquimia de la tierra", en: M. QUIJADA y Otros, Homogeneidad y Nación, Madrid, CSIC, pp.179-217.

-_(1996) "Los 'incas arios': historia, lengua y raza en la construcción nacional hispanoamericana", en: Histórica, vol. XX, $n^{\circ} 2$, diciembre, Lima, pp.246-269.

QUINTERO, Silvina (2002) "Geografías regionales en la Argentina. Imagen y valorización del territorio durante la primera mitad del siglo XX", en: Scripta Nova Revista electrónica de Geografía y Ciencias Sociales, vol. VI, no 127, octubre, Universidad de Barcelona, http://www.ub.es/geocrit/sn/sn-127.htm> .

ROMERO, Luis Alberto (1994) "El gobierno de Perón, 1943-1955", en: Breve Historia Contemporánea de la Argentina, Buenos Aires, FCE, pp. 129-177.

ROCK, David (1991) “El apogeo de Perón, 1946-1955" en Argentina 1516-1987. Desde la colonización española hasta Raúl Alfonsín, Buenos Aires, Alianza, pp.331-396.

TEOBALDO, Mirta y GARCÍA, Amelia Beatriz "Para ser patriota" el nacionalismo en los textos escolares argentinos desde 1910 a 
1952", en: AAVV, Image et transmission des savoirs dans le monde Ibérique et Ibéro-Américain, Tours, CIREMIA, en prensa.

\section{Resumen}

Como parte del proyecto de investigación “Libros de texto. Imágenes y representaciones. la construcción de la Patagonia en el imaginario escolar. Río Negro y Neuquén (1884-1957)" venimos trabajando sobre las representaciones de la Patagonia en los libros de textos estatales y salesianos anteriores y posteriores al período peronistafundamentalmente manuales y libros de lecturas. Algunas imágenes que hemos podido identificar en los textos trabajados son las que dan cuenta de: la Patagonia indígena y desierta, la Patagonia petrolífera, la Patagonia como fin de la Patria, a las que se suma la Patagonia turística asimilada a la Suiza Argentina. Estas representaciones fueron producto del análisis de contenidos históricos y geográficos y aquellos referidos a la economía hallados en los textos, plasmadas a través del lenguaje escrito tanto como del lenguaje icónico.

Siguiendo esta línea de trabajo y de un corpus documental de sesenta textos escolares que circularon durante el primer peronismo, seleccionamos para esta ponencia los Manuales Estrada (M.E.) de dicho período, teniendo en cuenta que de alguna manera, la práctica política hegemónica del gobierno otorgó un carácter incisivo a la introducción de determinados contenidos a través de los textos escolares.

Particularmente, y desde una perspectiva cualitativa, hacemos hincapié en los contenidos geográficos, históricos y de recursos naturales que permiten ir identificando algunos elementos para definir imágenes de la Patagonia, objetivo central del proyecto de Investigación.

Palabras clave: textos escolares, peronismo, manuales, Patagonia, representaciones.

The Promised Land: Patagonia in Estrada school textbooks during the first peronism

Summary

As part of the research project called "School textbooks. Images and representations. The building of Patagonia in the school imaginaries. Rio Negro and Neuquén (1884-1957)", we are working upon representations concerning Patagonia in school textbooks either state 
or religious ones (from the Salesian order), previous and subsequent to the peronist period. Some of the images we have been able to trace in such sources include those of Patagonia as indigenous and deserted, Patagonia as a source of oil, Patagonia as the end of our Homeland, as well as Patagonia for tourists when associated to an Argentinian Switzerland. Such representations were the result of an analysis of geographic, historical and economic contents as found within the texts, either in written language or iconography.

This line of work has been followed through the selection, for this paper, of a corpus composed of sixty school textbooks known as $M$ anuales Estrada from such period, bearing in mind that hegemonic government policies gave a crucial importance to the inclusion of certain contents through school textbooks.

From a qualitative perspective, we focus on historical, geographical and natural resources contents that allow to identify some elements to define Patagonia's images, as a central purpose of our research.

Key words: school textbooks, peronism, Patagonia, representations.

Recibido: 20/01/07; aceptado: 04/03/08. 